ANIMAL BEHAVIOUR, 2006, 71, 193-201

doi:10.1016/j.anbehav.2005.04.010

Available online at www.sciencedirect.com

science (1) Direct.

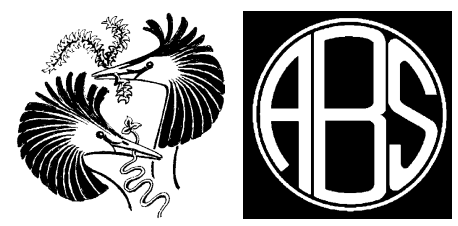

\title{
Reproductive skew in the Australian allodapine bee Exoneura robusta
}

\author{
PHILIPP LANGER*, KATJA HOGENDOORN†, MICHAEL P. SCHWARZ† \& LAURENT KELLER* \\ *Department of Ecology and Evolution, University of Lausanne \\ $\dagger$ School of Biological Sciences, Flinders University of South Australia \\ (Received 18 June 2004; initial acceptance 26 July 2004; \\ final acceptance 29 April 2005; published online 29 November 2005; MS. number: 8170R)
}

\begin{abstract}
Uneven sharing of reproduction (reproductive skew) among members of a cooperative animal society is one of the key features associated with advanced sociality and task specialization. Allocation of reproduction varies greatly among taxa, and reproductive skew models are evolutionary models that aim at explaining this variation. We tested reproductive skew theory using the Australian social allodapine bee Exoneura robusta. Reproductive skew was negatively correlated with relatedness, as predicted by the so-called tug-ofwar model and the restraint model. Both models assume that a dominant breeder in a society does not have full control over the allocation of reproduction among group members, in contrast to classical concession models. Overall, the tug-of-war model seems to account better for the evolution of reproductive sharing in E. robusta than the restraint model. However, neither model can be ruled out, and a tug-ofwar as well as a restraint model mechanism could apply in parallel in newly founded and overwintered colonies, respectively. This raises the possibility that skew models are not mutually exclusive and points to a more dynamic view on reproductive partitioning among breeders of an animal society.
\end{abstract}

(c) 2005 The Association for the Study of Animal Behaviour. Published by Elsevier Ltd. All rights reserved.

Animal societies show great variation in the partitioning of reproduction among group members (Keller \& Reeve 1994). Partitioning can range from strictly equitable breeding (referred to as low reproductive skew) to extreme reproductive skew such as in Atta ant colonies with a single breeder for up to 2.5 million nonreproducing individuals (Rettenmeyer \& Watkins 1978; Hölldobler \& Wilson 1990). Reproductive skew models are evolutionary models that provide theoretical explanations for this variation (Emlen 1982; Vehrencamp 1983; Reeve \& Ratnieks 1993; Keller \& Reeve 1994; Reeve \& Keller 1995; Cant 1998; Reeve 1998, 2000; Reeve et al. 1998; Johnstone \& Cant 1999a, b; Johnstone et al. 1999; Kokko \& Johnstone 1999; Ragsdale 1999; Cant \& Johnstone 2000; Crespi \& Ragsdale 2000; Reeve \& Emlen 2000; Reeve \& Jeanne

Correspondence and present address: P. Langer, Program for Evolutionary Dynamics, Harvard University, One Brattle Square, 6th floor, Cambridge, MA 02138, U.S.A. (email: planger@fas.harvard.edu). K. Hogendoorn is now at the School of Agriculture and Wine, Adelaide University, Adelaide SA 5005, Australia. M. P. Schwarz is at the School of Biological Sciences, Flinders University of South Australia, GPO Box 2100, Adelaide SA 5001, Australia. L. Keller is at the Department of Ecology and Evolution, University of Lausanne, Biology Building, 1015 Lausanne VD, Switzerland.
2003). Reproductive skew theory is furthermore broadly applicable to many other aspects of social evolution (e.g. Cant \& Johnstone 2000; Hamilton 2000; Reeve 2000), making it a potential harbinger of a unified theory of social behaviour (Keller \& Reeve 1994; Sherman et al. 1995).

Reproductive skew models can be put into two classes on the basis of their assumptions (Johnstone 2000; Reeve $\&$ Keller 2001). Transactional models make the assumption of a pre-existing hierarchy among breeders; so there is a dominant and a subordinate individual in the simplest case of a two-breeder society. Accordingly, two main types of transactional models exist. If the dominant controls the allocation of reproduction, the so-called 'concession' models (Emlen 1982; Vehrencamp 1983; Reeve \& Ratnieks 1993) predict that this dominant should yield just enough reproduction to a subordinate to make it favourable for the latter to stay in the group and cooperate peacefully, rather than to leave the group and reproduce independently. Dominants in two or more colonies can also compete for the services of a helping subordinate, a special case which is described in the so-called 'bidding game'. Alternatively, if the subordinate controls reproductive apportioning within the group (while the dominant controls group membership), the so-called 'restraint' model (Johnstone \& Cant 1999a) predicts that the subordinate 
should capture the largest share of reproduction that the dominant will tolerate before ejecting the subordinate. In both cases, one individual yields some reproduction to the other as an incentive to stay and cooperate peacefully, and group members thus engage in a sort of 'social contract' (Keller \& Reeve 1994). In contrast, tug-of-war models (Cant 1998; Reeve et al. 1998; Johnstone \& Cant $1999 b)$ do not make the assumption that either individual is able to control fully the allocation of reproduction. As a result, reproductive skew in a society is the outcome of a struggle over reproduction, which takes place at the expense of total group productivity.

In contrast to the abundance of theoretical models and model extensions (reviewed in Johnstone 2000), comparatively few studies have tested the predictions of reproductive skew theory in animal societies. Such studies have been conducted on a variety of invertebrate and vertebrate species (Reeve \& Nonacs 1992; Heinze 1995; Reeve \& Keller 1995; Jamieson 1997; Field et al. 1998; Hogendoorn \& Velthuis 1999; Reeve et al. 2000; Tibbetts \& Reeve 2000; Clutton-Brock et al. 2001; Fournier \& Keller 2001; Engh et al. 2002; Haydock \& Koenig 2002; Paxton et al. 2002; Seppa et al. 2002; Sumner et al. 2002; Langer et al. 2004a), but no clear trend has emerged in favour of a particular model when considering all species (Reeve \& Keller 2001). Experimental studies of further species are required if the various assumptions of all theoretical models are to be matched by variation among biological systems.

Our aim in this study was to test the predictions of reproductive skew models in the facultatively social allodapine bee Exoneura robusta by examining variation in the relatedness $(r)$ among breeders and the resulting partitioning of reproduction in colonies. The classic concession models predict a positive correlation between relatedness and skew, while the other models predict alternative outcomes (Table 1). Exoneura robusta has a number of important advantages for testing models of reproductive skew. First, the species is primitively social and has no morphological castes (Schwarz 1986; Schwarz et al. 1998), hence avoiding the problem of having to distinguish between skew for reproductive and nonreproductive offspring (Reeve \& Ratnieks 1993). Second, social nesting is facultative, in that females have the option to nest either solitarily or in groups (1-9 females per nest; Schwarz 1986, 1987). Group stability is therefore variable and can potentially influence the division of reproduction as predicted by transactional models. Third, a high proportion of nests contain two breeding females, the type of association for which most reproductive skew models have been developed, allowing a more direct comparison

Table 1. Predictions of the major skew models (Reeve \& Keller 2001)

\begin{tabular}{|ll|}
\hline Reproductive skew model & $\begin{array}{c}\text { Predicted association between } \\
\text { skew and breeder relatedness }(r)\end{array}$ \\
\hline Concession models & Positive \\
Bidding game & None \\
Restraint model & Negative \\
Tug-of-war models & None or negative \\
\hline
\end{tabular}

of models with the biological system. Fourth, females normally nest with related individuals, but also associate with unrelated individuals when no kin are available (Schwarz \& O'Keefe 1991b). Relatedness among breeders ( $r$ ) should therefore vary considerably in natural colonies. Fifth, this species is considered univoltine (Schwarz et al. 1998), so that it is unlikely that reproductive apportionment in a nest might be influenced by a female's breeding options in subsequent years (Kokko \& Johnstone 1999; Ragsdale 1999). Finally, E. robusta shows two broad forms of social organization. In newly founded nests, all cofounding females are reproductive, making these colonies quasisocial and without apparent hierarchies (Schwarz 1986). In contrast, in reused nests (i.e. nests entering their second or later year of use) the first-eclosed female assumes a clear reproductively dominant status, giving rise to semisocial colonies (Schwarz \& O'Keefe 1991b; Schwarz \& Woods 1994; Schwarz et al. 1998). In such overwintering nests, the dominant female becomes a guard during autumn and winter (Hogendoorn \& Schwarz 1998) and prevents any of her nestmates that have had extranidal contact with unrelated males from re-entering their nests, thus excluding potential reproductive rivals (Bull et al. 1998).

The absence or presence of a dominant individual within nests of the same species (newly founded or overwintered nests, respectively) allows us to assess the applicability of reproductive skew models, of which some are based on the premise that there is a dominant individual that controls group membership. In contradiction to the species' suitability for testing variations in relatedness $(r)$ and reproductive skew, other parameters predicted to influence reproductive sharing (such as $x$, the subordinate's solitary nesting success, or $k$, the productivity benefits of cooperative nesting, which are predicted to affect skew under the concession, restraint and partly under the bidding-game models; Reeve \& Keller 2001) show no natural variation and cannot be manipulated in this species, partly because nesting sites are not a limiting resource in natural populations, and cooperative nesting is not a response to limited nesting sites (Schwarz 1994). We therefore limited our analysis to comparing relatedness and reproductive skew.

Previous studies of E. robusta estimated reproductive partitioning among breeders from their ovary development; hence no precise measures of skew exist. In this study, we used newly developed microsatellite markers (Langer et al. 2004b) to assign brood in two- and threefemale nests to the genetic mother(s), and we thus present the first exact measures of reproductive skew in E. robusta. We also attempted to manipulate breeder relatedness in colonies as a potential tool to assess the effect of relatedness on reproductive skew more rigorously.

\section{METHODS}

Two groups of colony samples were used for this study. We used natural colonies collected in the wild to compare relatedness and reproductive partitioning among breeders. We also attempted to manipulate relatedness among potential breeders in seminatural nests. 


\section{Natural Colonies}

We collected 40 naturally occurring nests from Toolangi State Forest, $1 \mathrm{~km}$ southeast of Toolangi, Victoria, Australia, on 19 January 2000. Brood development is highly synchronized in this species (Schwarz et al. 1998), and nests collected at this time contained parental-generation females and their nearly mature brood, mostly comprising postfeeding larvae and pupae. This meant that we retrieved each nest's total brood before they were able to disperse (Schwarz 1986). We sampled nests from areas with similar tree cover, nesting site abundance, floral resources and insolation to ensure that conditions during brood rearing had been similar and that other factors potentially affecting skew were comparable. We collected colonies from both newly founded nests (established in the preceding spring) and reused nests ( $>1$ year old). These two nest types can be distinguished by the coloration of the nest lumen wall: newly founded nests have a clean appearance with only yellow traces of pollen, whereas reused nests have darkly mottled coloration, including black and brown traces caused by the ageing of pollen and nectar from the previous year's broodrearing activities (Schwarz 1986).

\section{Seminatural Colonies}

In 1999, we attempted to influence relatedness in natural colonies in the wild similar to a study in a close sister species (Langer et al. 2004a), but our experiment yielded a very restricted nest-founding rate after 1 year (seven nests founded out of 200 nests set out). Because of this limited success, we used a more controlled approach to manipulate relatedness by constructing seminatural nests containing related or unrelated females. Following the methods of Schwarz (1986), we collected 63 natural nests at Toolangi State Forest between 23 and 27 September 2000. This was just before the natural dispersal and nest-founding period, which is restricted to approximately 2 weeks in this species (Schwarz 1986). Colonies were taken to Flinders University, Adelaide, South Australia, and opened in a controlled temperature room $\left(12^{\circ} \mathrm{C}\right)$ to minimize bee activity.

Bees from the collected colonies were shared out among seminatural nests, constructed by punching a hole $(6 \mathrm{~mm}$ in diameter and approximately $5 \mathrm{~cm}$ in length) into the soft centre of an abscised tree fern frond, the natural nesting substrate of E. robusta. These seminatural nests were thus similar to the burrows naturally excavated by E. robusta in the wild. Since nestmates are usually related (Schwarz 1987), we constructed nests containing related individuals by placing two females from the same source colony into a frond (high-relatedness treatment). A total of 27 related 'colonies' were constructed in this way. To construct nests containing unrelated females (low-relatedness treatment), we placed two females from remote source colonies into a tree fern frond and assembled a total of 27 'colonies' in this treatment as well. For feeding, we attached a small flight cage $(4.5 \mathrm{~cm}$ long and $6 \mathrm{~cm}$ diameter) to the entrance of each nest and inserted a capillary tube filled with honey-water (50:50) as a food source.
We then allowed the females to settle in the tree fronds. To simulate a normal circadian rhythm during this founding period, we moved the nests from the controlled temperature room $\left(12^{\circ} \mathrm{C}\right)$ into a warm chamber $\left(22^{\circ} \mathrm{C}\right)$ in the morning and put the nests back into the $12^{\circ} \mathrm{C}$ room in the evening. After 2 weeks, most females had further excavated the burrow and hence settled in the nesting substrate.

On 15 October 2000, we put the fronds containing the nests in an outside fenced compound $(6 \times 15 \mathrm{~m})$ on the campus of Flinders University. As the climate around Flinders University is hotter than the natural habitat at Toolangi State Forest, we chose shady areas under trees to minimize heat stress. No natural populations of E. robusta occur in this area, precluding any contamination of these colonies with females from outside the experiment. The breeding area was limited to a radius of $30 \mathrm{~m}$ and contained no alternative substrate for nesting, but included naturally occurring plants for feeding such as Acacia, Eucalyptus and several native flowering bushes (Hebe, Eremophila and Hibbertia). This allowed us to control other factors potentially influencing reproductive skew, such as alternative nest site abundance or flower abundance, and ensured similar brood-rearing conditions. Nests were collected on 6 December 2000.

\section{Dissection and Genetic Analyses}

Before dissection and genetic analyses, we cooled the bees to $4{ }^{\circ} \mathrm{C}$ which immobilizes them and makes them numb. We then cut the abdomen and placed head and thorax into vials containing $100 \%$ alcohol, while pulling off the wings and gluing them onto sticky tape for measurement. The abdomen was preserved in Kahle's solution for later dissection. To determine reproductive skew among females, we genotyped the entire nest contents (adults, brood and eggs, comprising 567 individuals from 65 nests in total) at six highly polymorphic microsatellite loci (R115, N60, N81, R74, N83 and R32r) using previously reported conditions (Langer et al. 2004b). Analysis of individuals with more than one nonamplifying locus was repeated, and each individual was thus scored between one and four times. Gels were analysed several times by one to three independent persons to check for consistency in genotype scoring. From dissected adult individuals we recorded sizes of oocytes, insemination status, the presence of yellow bodies, wing length and wing wear (Schwarz 1986).

The combined genetic and dissection data allowed us unambiguously to identify breeding females and to determine the maternity of offspring in all nests. Relatedness between breeders was calculated with the program Relatedness 5.0.8 (Queller \& Goodnight 1989). Given that cofoundresses in natural nests are usually related (Schwarz et al. 1998), we bias-corrected the population allele frequency by nests to exclude putative relatives from contributing to the allele frequency. Nests were weighted equally and standard errors of relatedness values were obtained by jackknifing over loci (for within-nest relatedness) or over colonies (for relatedness per treatment). 


\section{Reproductive Skew and Productivity}

For nests where several breeders and brood were present, we used parentage data to calculate reproductive skew. Among the different measures that quantify skew (reviewed in Nonacs 2003), we calculated the indices $B$ (Nonacs 2000), $B_{\mathrm{s}}$ (Nonacs 2003), $S$ (Keller \& Vargo 1993) and $S_{\mathrm{c}}$ (Keller \& Krieger 1996). The conclusions from each of these measures were identical, and we therefore only present skew using the $B$ index. This index yields positive values if skew among group members is higher than expected under random allocation of reproduction, zero if the allocation is random, and negative values if the distribution of reproduction is more even than expected by chance. We assessed total reproductive skew, including male and female offspring, because nests of E. robusta contain low numbers of offspring (Schwarz 1994) and show a female-biased sex allocation ratio, especially in smaller nests (Schwarz 1988, 1994). The assessment of total offspring per colony is justified by the absence of a significant trade-off (Fournier \& Keller 2001) among breeders for male and female production in colonies (Pearson correlation between the relative contribution of the most productive breeder to male and female production within each colony containing both male and female offspring: $\left.r_{22}=-0.19, P=0.36\right)$.

Overall, 55 nests contained sufficient females and brood to calculate skew: of these, 48 nests contained two females, six nests contained three and one nest contained four breeding females. As we reached the same conclusions when considering all multifemale nests or just the two-female colonies, we present the results with all multifemale nests together. Colony productivity is presented as the total number of offspring produced per nest. However, results were identical when considering per capita productivity, that is, brood production per female.

\section{Statistical Analyses}

Relatedness, skew and productivity values were tested for normality with the extended Kolmogorov-Smirnov test of Dallal \& Wilkinson (1986) before the use of parametric tests. We also performed $F$ ratio tests to verify equal variances prior to any $t$ test. When applying linear regressions, we tested the residuals for normality and ensured that the data points did not deviate from a straight line by runs tests. Statistical tests are two tailed unless explicitly stated (i.e. the power calculation for correlation takes place in a given direction). Power analyses were done with the program GPower from Erdfelder et al. (1996).

\section{RESULTS}

Analyses of pedigree and insemination status revealed that the breeding females probably consisted of a mother and her daughter in one natural and one seminatural nest. The natural nest was a reused (overwintered) colony, and only the daughter was reproductively active. In contrast, both females (mother and daughter) had produced offspring in the newly founded seminatural nest. These two nests were excluded from the following analyses because a matrifilial structure is expected to affect skew (Reeve \& Keller 1995; Reeve et al. 1998).

\section{Natural Colonies}

We retrieved 34 natural nests where skew could be calculated (23 newly founded and 11 reused nests). Mean breeder relatedness was $r \pm \mathrm{SE}=0.41 \pm 0.06$ in newly founded nests and $0.41 \pm 0.08$ in reused nests, which were not significantly different from each other (unpaired $t$ test: $\left.t_{32}=0.08, P=0.94\right)$. Overall, the average relatedness was $r=0.41 \pm 0.05$, with individual relatedness values per nest ranging from unrelated $(r \pm \mathrm{SE}=$ $-0.15 \pm 0.10)$ to highly related breeders $(r=0.87 \pm$ $0.14)$. Reproductive skew in newly founded colonies was $B \pm \mathrm{SE}=0.04 \pm 0.03$ and not statistically different from overwintered nests $(B=0.06 \pm 0.05$; unpaired $t$ test: $\left.t_{32}=0.48, P=0.63\right)$. Mean reproductive skew in natural nests thus came to $0.04 \pm 0.03$, marginally not significantly different from zero (one-sample $t$ test: $t_{33}=1.72, P=0.09$ ) with a power of 0.39 (two-tailed power analysis: effect size $f=0.30, \alpha=0.05, \delta=1.72, n=34)$.

\section{Seminatural Colonies}

We recovered 19 seminatural nests where skew could be calculated (12 from the high-relatedness and 7 from the low-relatedness treatments). Relatedness among breeders ranged from $r \pm \mathrm{SE}=0.05 \pm 0.11$ in the low-relatedness treatment to $0.76 \pm 0.16$ in the high-relatedness treatment. Mean breeder relatedness was $0.38 \pm 0.05$ in the high-relatedness treatment and $0.31 \pm 0.12$ in the low-relatedness treatment. Despite a tendency for higher relatedness in the high-relatedness treatment, this difference was not significant (unpaired $t$ test: $t_{17}=0.61, P=0.55$ ); thus mean relatedness in seminatural colonies was $0.35 \pm 0.05$. Reproductive skew did not differ significantly between the high-relatedness $(B \pm \mathrm{SE}=0.11 \pm 0.05)$ and the low-relatedness $(0.06 \pm 0.07)$ treatments either (unpaired $t$ test: $\left.t_{17}=0.58, P=0.57\right)$. The average reproductive skew in seminatural colonies came to $0.09 \pm 0.04$, significantly greater than zero (one-sample $t$ test: $t_{18}=2.15, P<0.05$ ).

\section{Combined Data}

Since seminatural colonies showed no significant differences from natural colonies in either relatedness or skew (unpaired $t$ tests: all NS), we combined both groups of nests and analysed data for all nests combined $(N=53)$. Of this data set, 42 colonies consisted of newly founded nests and 11 colonies were reused (overwintered).

The mean relatedness over all nests $(r \pm \mathrm{SE}=0.39 \pm$ 0.04) was significantly greater than zero (one-sample $t$ test: $\left.t_{52}=10.77, P<0.0001\right)$. Newly founded nests $(r=0.39 \pm 0.04)$ showed no significant difference from reused colonies $(r=0.41 \pm 0.08$; unpaired $t$ test: $\left.t_{51}=0.23, P=0.82\right)$. Nests contained a mean $\pm \mathrm{SE}$ of $6.7 \pm 0.5$ offspring per nest, of which the most productive 
female produced on average $4.7 \pm 0.4$ offspring. Offspring production among breeders was shared with an overall reproductive skew of $B \pm \mathrm{SE}=0.06 \pm 0.02$, a value significantly greater than zero (one-sample $t$ test: $t_{52}=2.73$, $P=0.009$ ). When considered separately, reproductive skew was significantly greater than zero in newly founded colonies $\quad(B \pm \mathrm{SE}=0.06 \pm 0.03 ; \quad$ one-sample $t$ test: $\left.t_{41}=2.37, P=0.02\right)$, but not in reused nests $(0.06 \pm 0.05$; $\left.t_{10}=1.29, P=0.22\right)$. However, this probably reflects a difference in sample size, as reproductive skew was similar in (0.06), and not significantly different between, both types of colonies (unpaired $t$ test: $t_{51}=0.02, P=0.98$ ).

Across all colonies, we found a significant negative correlation between relatedness and reproductive skew (Pearson correlation: $r_{51}=-0.39, P=0.004$; Fig. 1). The correlation was also negative in newly founded and reused colonies considered separately (Fig. 2), but reached significance only in newly founded nests (Pearson: $r_{40}=-0.45$, $P<0.003)$, whereas reused colonies showed a nonsignificant negative correlation $\left(r_{9}=-0.13, P=0.70\right)$. The power of this nonsignificant correlation in reused nests was only 0.11 , however (one-tailed power analysis: $r=0.13$, $\alpha=0.05, \delta=0.44$ ), and the linear regression line from newly founded colonies was not statistically different from the line from reused nests in slope (ANCOVA: $\left.F_{1,49}=0.93, P=0.34\right)$ or elevation $\left(F_{1,50}=0.02, P=0.90\right)$.

The mean number of offspring produced was similar in natural $(6.2 \pm 0.6, N=34)$ and seminatural nests (7.5 $\pm 0.8, N=19$; unpaired $t$ test: $\left.t_{51}=1.3, P=0.18\right)$. Newly founded colonies did not show significantly different offspring production $(6.3 \pm 0.5, N=42)$ from reused nests $\left(8.0 \pm 1.2, \quad N=11\right.$; unpaired $t$ test: $t_{51}=1.4$, $P=0.16)$; thus overall mean productivity was $6.7 \pm 0.5$ $(N=53)$. The number of offspring per nest was not correlated with reproductive skew (Pearson correlation: $\left.r_{51}=0.21, P=0.13\right)$ or breeder relatedness $\left(r_{51}=0.15\right.$, $P=0.27)$. This was also true for newly founded and reused nests considered separately (Pearson correlations: all NS).

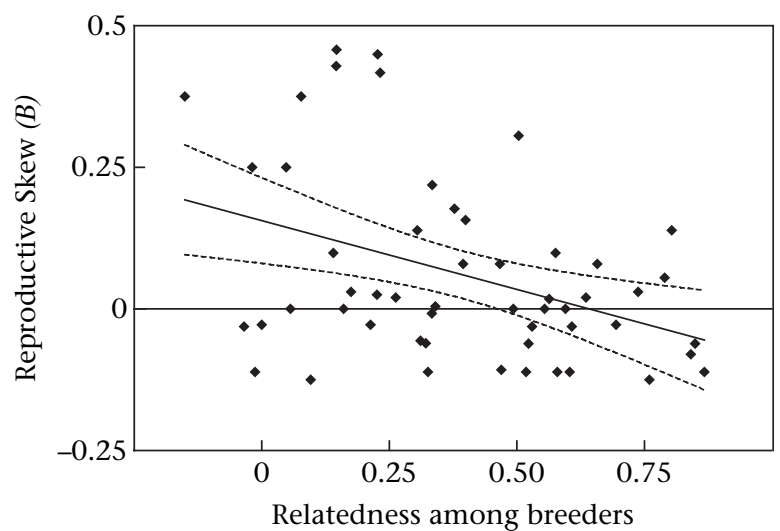

Figure 1. Correlation between a nest's reproductive skew and breeder relatedness across all colonies (natural nests and nests from the relatedness treatment, $N=53$ ). Each symbol represents a colony; the straight line shows the linear regression with its $95 \%$ confidence interval $\left(F_{1,51}=9.16, P=0.004\right)$. The slope of the linear regression is $-0.24 \pm 0.08$, goodness of fit is $r^{2}=0.15$, and data points showed no significant departure from a straight line (runs test: $P=0.73$ ).

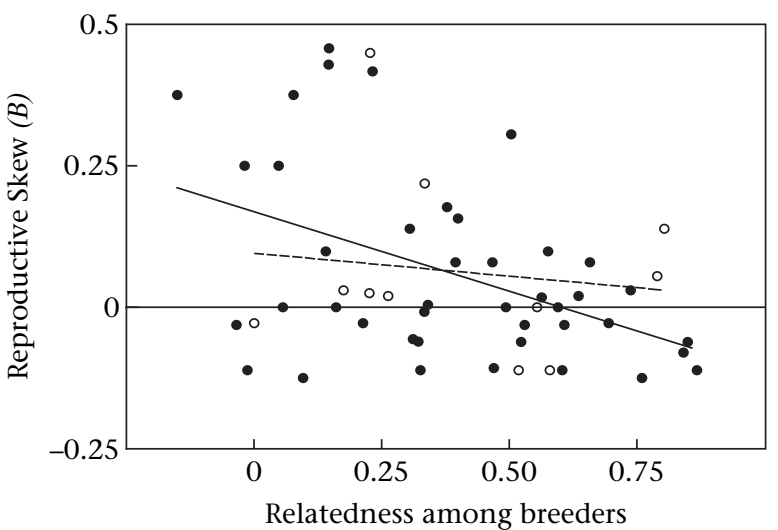

Figure 2. Correlation between reproductive skew and breeder relatedness across newly founded $(0 ; N=42)$ and reused colonies $(O ; N=11)$ separately. The solid straight line shows the linear regression of newly founded nests $\left(F_{1,40}=10.1, P<0.003\right.$, goodness of fit $\left.r^{2}=0.20\right)$; the dotted line represents the linear regression of overwintered nests $\left(F_{1,9}=0.16, P=0.70\right.$, goodness of fit $\left.r^{2}=0.02\right)$. Data points showed no significant departure from straight lines, either in newly founded (runs test: $P=0.80$ ) or in overwintered nests $(P=0.61)$.

\section{DISCUSSION}

\section{Set-up in Natural and Seminatural Colonies}

Our attempt to manipulate relatedness in seminatural nests failed. Although breeders in the high-relatedness treatment were slightly more related than in the lowrelatedness treatment, the difference was not significant. This contrasts with an experiment conducted in the closely related species Exoneura nigrescens where the same manipulations led to significant differences in relatedness between treatment groups (Langer et al. 2004a).

The present experiment failed because of the occurrence of related females in nests of the low-relatedness treatment. In contrast, nests of the high-relatedness treatment contained only related breeders as intended. The most likely explanations for the presence of related breeders in the low-relatedness treatment are nest switching and teaming up of former nestmates. Nest switching is known to occur in E. robusta, with entire colonies sometimes moving into other established colonies in observation nests (Melna \& Schwarz 1994). In our set-up, colour-coded nests from the high- and low-relatedness treatments were set out in the same area during brood rearing to allow similar conditions (see Methods). If two females of the highrelatedness treatment moved into an abandoned nest of the low-relatedness treatment, one would indeed retrieve related females in the low-relatedness nest. The second potential explanation for related breeders in the unrelated treatment is teaming up of former nestmates. In the low-relatedness treatment, former nestmates were split up into different colonies to found nests with unrelated females. During brood rearing, all colonies were again set out close to each other, and it is conceivable that former nestmates teamed up again at this time after having excavated separate nests. 


\section{Combined Data Set}

Since experimental nests showed no difference in relatedness, skew or productivity between the high- and low-relatedness treatments, and because seminatural nests did not differ significantly from natural nests in any of these measures, we presented only the results of the analyses obtained with all nests combined.

The genetic analyses revealed that reproductive females were on average significantly related in both newly founded and reused nests. Breeders in natural nests ranged from unrelated to highly related, consistent with the observation that females prefer nesting with relatives but also associate with unrelated individuals when no kin are available (Schwarz \& O'Keefe 1991b). We found no significant difference in relatedness between newly founded and reused nests. In contrast, Schwarz (1987) reported a significant relatedness difference between newly founded $(r \pm \mathrm{SE}=0.60 \pm 0.06, N=88)$ and overwintered $(0.49 \pm 0.06, N=98)$ nests based on allozyme data. The study found that breeders were more related in newly founded colonies and explained this by active kin association of females for nest founding (Schwarz \& Blows 1991). Compared to Schwarz's (1987) values, we found a similar relatedness in overwintered nests (unpaired $t$ test with Welch's correction: $t_{24}=0.80, P=0.44$ ), but our results indicate a significantly lower relatedness in newly founded colonies $\left(t_{127}=2.84, P=0.005\right)$. This would be compatible with Bull \& Adams's (2000) finding that females do not discriminate between kin of high and low relatedness during the founding of a new nest, but simply choose to nest with familiar individuals from the same natal nest.

Overall reproductive skew was low but significantly greater than zero, the value expected under random partition of reproduction among females. Skew was not significantly different between newly founded and reused (overwintered) colonies. The fact that skew was greater than zero in newly founded nests, but not in reused colonies may merely stem from the smaller sample size in reused nests (and hence the larger variance). Our finding of equal skew in newly founded and overwintered colonies contrasts with previous studies using relative ovary development as a measure of skew (Schwarz \& O'Keefe 1991a, b; Schwarz \& Woods 1994). These studies concluded that there is a higher skew in overwintered nests than in newly founded colonies. This was deduced because the first-eclosed dominant female in overwintered colonies showed more developed ovaries than other 'secondary' reproductives, and a third type of 'worker' female even had permanently undeveloped ovaries. In contrast, cofoundresses of newly founded nests showed very similar ovarian development, suggesting little or no skew in these colonies.

There are two possible explanations for the discrepancy between our results and the findings of previous studies. The first is that maternity is not directly correlated with the presence of large oocytes in the ovaries as recorded in earlier studies, since ovaries may shrink or even degenerate after egg laying (e.g. Michener 1971). In support of this, we found inconsistencies between a female's reproductive status from dissections and the genetic nest data at an incidence of $13 \%$ (16 of 120 dissections). In these cases, the genetic egg-layer had only small oocytes or a seemingly empty spermatheca despite having produced female offspring. Alternatively, it is possible that a significant skew occurs only in nests containing large numbers of females. In the present study, we restricted our analyses to nests containing mainly two females. By contrast, nests with three (Schwarz \& O'Keefe 1991a) or four (Schwarz \& O'Keefe 1991b; Schwarz \& Woods 1994) females had been considered in previous analyses.

Reproductive skew was negatively correlated with relatedness in both the newly founded and reused natural colonies. However, the association was significant only for newly founded colonies. It is unclear whether the lack of significant association for reused nests reflects the lower sample size of this group (11 nests) or a genuine difference in the role of relatedness on reproductive skew between overwintered and newly founded nests in E. robusta. A negative influence of relatedness on reproductive sharing suggests that females are able to assess their nestmate's relatedness, despite the finding that they do not seem to discriminate between related and unrelated former nestmates during nest founding (Bull \& Adams 2000). This supports the view of Schwarz et al. (1998) that cooperative nesting in this species is primarily a response to the large benefits of increased brood survival and communal colony defence. Relatedness during the founding stage could therefore play a minor role even if females are capable of kin discrimination.

Among reproductive skew theory, two of the four main reproductive skew models are inconsistent with the finding that reproductive skew was negatively correlated with relatedness (Table 1). The classic concession models predict a positive correlation between relatedness and skew while the 'bidding game' predicts no correlation. Thus, both models can be ruled out for E. robusta. This is further confirmed by the nest productivity results where no significant correlation between nest productivity and skew occurred, whereas concession models would normally predict a positive association between these two parameters (Reeve et al. 1998, 2000).

In contrast, both the tug-of-war and the restraint models predict a negative correlation between relatedness and reproductive skew (Table 1) and are in line with our findings. Precise discrimination between these two models would require the availability of additional parameters potentially influencing skew, such as $x$ (the subordinate's solitary nesting success) or $k$ (the productivity benefits of cooperative nesting), both of which are predicted to affect skew under the restraint model, but not under the tug-ofwar model (Reeve \& Keller 2001). As outlined earlier, neither of these parameters varies under natural conditions in E. robusta, besides being inaccessible for manipulation (Schwarz 1994). To pin down the model that is more probable in E. robusta, we consider how the assumptions of each model are met in newly founded and overwintered nests separately.

The assumptions of the restraint model are compatible with life cycle patterns in reused (overwintered) nests, but not in newly founded nests. This model assumes a clear 
dominant/subordinate hierarchy, where the subordinate can acquire unsanctioned reproduction and is constrained only by the threat of eviction by the dominant, as the latter controls group membership (Johnstone \& Cant 1999a). This condition could be met in overwintered colonies of E. robusta, where the first-eclosing female is known to assume dominant status (Schwarz \& O'Keefe 1991b; Schwarz \& Woods 1994). Before the brood-laying period, the dominant evicts subordinates that have been in contact with a foreign male (Bull et al. 1998), a clear sign that it controls group membership as predicted by the restraint model. To prevent eviction, subordinates must probably refrain from mating before the dominant starts egg laying. During the egg-laying period, the subordinates' egg production lags behind the dominants' brood rearing (Schwarz et al. 1998), and it is conceivable that the subordinate has to restrain its egg laying to avoid eviction by the dominant. The restraint model predicts further that under high breeder relatedness, the dominant should tolerate ample offspring production, compatible with the overall low skew in our study given the high average breeder relatedness. Taken together, the predictions and assumptions of the restraint model are fully compatible with the social structure in overwintered nests of E. robusta.

Conversely, the social structure in newly founded nests violates the restraint model's basic assumption of a dominant/subordinate hierarchy where the dominant controls group membership. Cofoundresses in newly founded nests cooperate in an egalitarian way and show no dominant/subordinate hierarchy (Schwarz 1986; Schwarz \& O'Keefe 1991a). Apparently, no individual controls group membership, and eviction of one colony member by another has never been observed (P. S. Hurst, unpublished data), although no observations have been made during the brood-rearing period. Therefore, the basis of the restraint model seems less likely to hold true in newly founded nests.

On the other hand, the assumptions of tug-of-war models are compatible with life cycle patterns in both newly founded and overwintered nests, and may help explain additional findings of group productivity. Tug-ofwar models do not consider issues of group stability, and breeders simply engage in a struggle over apportionment of reproduction, so that the resulting skew represents a compromise between the conflicting optima of each breeder (Reeve et al. 1998). This mechanism seems well suited to explain sharing of reproduction in newly founded colonies of E. robusta, where all cofoundresses reproduce and where no dominant/subordinate hierarchy exists. Importantly, the tug-of-war models can account for the situation in overwintered colonies with a dominant/subordinate hierarchy as well. Reeve et al. (1998) suggested that a dominance/subordinate hierarchy can exist because of eclosion order or other inherent differences between females, and that the subordinate may simply be less efficient than the dominant in converting resources into an increased share of reproduction, resulting in it reproducing less. Dominance in overwintered nests of E. robusta is indeed defined by eclosion order (Schwarz \& O'Keefe 1991b; Schwarz \& Woods 1994), and the subordinate is potentially less efficient in converting resources into an increased share of reproduction because of the later onset of its brood production. The precise means by which subordinance (and the decreased efficiency in converting resources) is enforced and maintained by the dominant are presently unknown, although pheromonal signals produced by dominants have been implicated in the maintenance of reproductive hierarchies of Exoneura (O'Keefe \& Schwarz 1990). Under the tug-of-war model, the eviction of a mated subordinate by the dominant before the egg-laying period (Bull et al. 1998) can be a manifestation of the struggle that takes place between females for an increased share of reproduction.

Further support for the tug-of-war models comes from the observation that aggressive behaviour among nestmates is very rare in E. robusta (Melna \& Schwarz 1994; K. Hogendoorn, personal observation). Tug-of-war models indeed predict low levels of struggle over reproduction when breeders are highly related (Reeve et al. 1998). A further, related prediction of tug-of-war models is a positive association between relatedness and productivity (Reeve et al. 1998). This is because related females should allocate less energy to fighting over reproduction. Hence, productivity should increase with relatedness because fewer resources are devoted to the struggle over reproduction. Despite a positive trend between relatedness and productivity, we did not find a significant positive correlation between the two variables. The lack of significance could stem from an insufficient sample size, or be explained if the female's resources (devoted to either struggle over reproduction or reproductive output) are not the limiting factor to brood production in E. robusta. Overall, the tug-of-war model still offers a plausible explanation for the mechanism of reproductive sharing in both newly founded and overwintered nests of E. robusta.

Finally, the presence of two potential mother-daughter associations was surprising because E. robusta was generally considered univoltine (Schwarz 1986; Schwarz et al. 1998). However, it is unlikely that social queuing for subsequent reproduction is a widely applicable strategy and that it explains reproductive skew in colonies, because offspring production by an older generation female occurred in only one of 55 nests (overall frequency of $1.8 \%$ ). Our findings suggest that $E$. robusta is not compellingly univoltine, confirming previous observations of P. Hurst (unpublished data) where some females presumably survived for more than one winter in observation nests.

In conclusion, our study shows that reproductive skew is low but greater than zero in E. robusta, indicating that division of reproduction is not uniform among breeders. Skew and relatedness are negatively correlated, and two reproductive skew models are compatible with such negative association, the tug-of-war and the restraint models. Both models predict that a dominant breeder in a society is unable to control fully the allocation of reproduction among group members, in contrast to predictions from classical concession models. Thus, control over reproduction can be limited even within small colonies of insects, not only in large animal groups (Clutton-Brock 1998). Between the two plausible models, the assumptions of the restraint model are likely to be met in reused (overwintered) 
colonies, whereas the basic assumptions of the tug-of-war models apply for both newly founded nests and reused colonies. Overall, the tug-of-war model seems to account better as a possible single model for reproductive sharing in E. robusta, and was also found to be the best model to explain reproductive skew in the closely related sister species E. nigrescens (Langer et al. 2004a). However, neither model can be ruled out in the case of E. robusta, and the tug-of-war and the restraint models could also apply simultaneously in newly founded and overwintered colonies, respectively. Reproductive dominance might be settled in newly founded colonies according to the tug-of-war model, but take place according to the assumptions of the restraint model in reused nests once the first-eclosed offspring assumes dominance status. This hypothesis would raise the possibility that skew models are not mutually exclusive and points to a more dynamic view on reproductive partitioning among breeders of an animal society.

\section{Acknowledgments}

We thank Catherine Roger and Grégoire Deppierraz for help in genotyping, Nelly DiMarco for extractions, John Zammit for help in setting up field experiments and Phil Jordan and the Evolutionary Biology Unit of the South Australian Museum for the use of their facilities. We are grateful to Rob Hammond and four anonymous referees who made very helpful comments on the manuscript. This work was supported by grants from the Swiss National Science Foundation and the Australian Research Council (to L. Keller and M. P. Schwarz, respectively).

\section{References}

Bull, N. J. \& Adams, M. 2000. Kin associations during nest founding in an allodapine bee Exoneura robusta: do females distinguish between relatives and familiar nestmates? Ethology, 106, 117-129.

Bull, N. J., Mibus, A. C., Norimatsu, Y., Jarmyn, B. L. \& Schwarz, M. P. 1998. Giving your daughters the edge: bequeathing reproductive dominance in a primitively social bee. Proceedings of the Royal Society of London, Series B, 265, 1411-1415.

Cant, M. A. 1998. A model for the evolution of reproductive skew without reproductive suppression. Animal Behaviour, 55, 163-169.

Cant, M. A. \& Johnstone, R. A. 2000. Power struggles, dominance testing, and reproductive skew. American Naturalist, 155, 406-417.

Clutton-Brock, T. H. 1998. Reproductive skew, concessions and limited control. Trends in Ecology and Evolution, 13, 288-292.

Clutton-Brock, T. H., Brotherton, P. N. M., Russell, A. F., O'Riain, M. J., Gaynor, D., Kansky, R., Griffin, A., Manser, M., Sharpe, L., Mcllrath, G. M., Small, T., Moss, A. \& Monfort, S. 2001. Cooperation, control, and concession in meerkat groups. Science, 291, 478-481.

Crespi, B. J. \& Ragsdale, J. E. 2000. A skew model for the evolution of sociality via manipulation: why it is better to be feared than loved. Proceedings of the Royal Society of London, Series B, 267, 821-828.

Dallal, G. E. \& Wilkinson, L. 1986. An analytic approximation to the distribution of Lilliefors test statistic for normality. American Statistician, 40, 294-296.

Emlen, S. T. 1982. The evolution of helping. I. An ecological constraints model. American Naturalist, 119, 29-39.

Engh, A. L., Funk, S. M., Van Horn, R. C., Scribner, K. T., Bruford, M. W., Libants, S., Szykman, M., Smale, L. \& Holekamp, K. E.
2002. Reproductive skew among males in a female-dominated mammalian society. Behavioral Ecology, 13, 193-200.

Erdfelder, E., Faul, F. \& Buchner, A. 1996. GPOWER: a general power analysis program. Behavior Research Methods, Instruments and Computers, 28, 1-11.

Field, J., Solis, C. R., Queller, D. C. \& Strassmann, J. E. 1998. Social and genetic structure of paper wasp cofoundress associations: tests of reproductive skew models. American Naturalist, 151 545-563.

Fournier, D. \& Keller, L. 2001. Partitioning of reproduction among queens in the Argentine ant, Linepithema humile. Animal Behaviour, 62, 1039-1045

Hamilton, I. M. 2000. Recruiters and joiners: using optimal skew theory to predict group size and the division of resources within groups of social foragers. American Naturalist, 155, 684-695.

Haydock, J. \& Koenig, W. D. 2002. Reproductive skew in the polygynandrous acorn woodpecker. Proceedings of the National Academy of Sciences of the U.S.A., 99, 7178-7183.

Heinze, J. 1995. Reproductive skew and genetic relatedness in Leptothorax ants. Proceedings of the Royal Society of London, Series $B$, 261, 375-379.

Hogendoorn, K. \& Schwarz, M. P. 1998. Guarding specialisation in pre-reproductive colonies of the allodapine bee Exoneura bicolor Ethology Ecology and Evolution, 10, 67-77.

Hogendoorn, K. \& Velthuis, H. H. W. 1999. Task allocation and reproductive skew in social mass provisioning carpenter bees in relation to age and size. Insectes Sociaux, 46, 198-207.

Hölldobler, B. \& Wilson, E. O. 1990. The Ants. Cambridge, Massachusetts: The Belknap Press of Harvard University Press.

Jamieson, I. G. 1997. Testing reproductive skew models in a communally breeding bird, the pukeko, Porphyrio porphyrio. Proceedings of the Royal Society of London, Series B, 264, 335-340.

Johnstone, R. A. 2000. Models of reproductive skew: a review and synthesis. Ethology, 106, 5-26.

Johnstone, R. A. \& Cant, M. A. 1999a. Reproductive skew and the threat of eviction: a new perspective. Proceedings of the Royal Society of London, Series B, 266, 275-279.

Johnstone, R. A. \& Cant, M. A. 1999b. Reproductive skew and indiscriminate infanticide. Animal Behaviour, 57, 243-249.

Johnstone, R. A., Woodroffe, R., Cant, M. A. \& Wright, J. 1999. Reproductive skew in multimember groups. American Naturalist, 153, 315-331.

Keller, L. \& Krieger, M. J. B. 1996. Mating success of male birds. Nature, 380, 208-209.

Keller, L. \& Reeve, H. K. 1994. Partitioning of reproduction in animal societies. Trends in Ecology and Evolution, 9, 98-102.

Keller, L. \& Vargo, E. L. 1993. Reproductive structure and reproductive roles in colonies of eusocial insects. In: Queen Number and Sociality in Insects (Ed. by L. Keller), pp. 16-44. Oxford: Oxford University Press.

Kokko, H. \& Johnstone, R. A. 1999. Social queuing in animal societies: a dynamic model of reproductive skew. Proceedings of the Royal Society of London, Series B, 266, 571-578.

Langer, P., Hogendoorn, K. \& Keller, L. 2004a. Tug-of-war over reproduction in a social bee. Nature, 428, 844-847.

Langer, P., Molbo, D. \& Keller, L. 2004b. Polymorphic microsatellite loci in allodapine bees for investigating the evolution of social behaviour. Molecular Ecology Notes, 4, 303-305.

Melna, P. A. \& Schwarz, M. P. 1994. Behavioral specialization in pre-reproductive colonies of the allodapine bee Exoneura bicolor (Hymenoptera, Anthophoridae). Insectes Sociaux, 41, 1-18.

Michener, C. D. 1971. Biologies of African allodapine bees (Hymenoptera, Xylocopinae). Bulletin of the American Museum of Natura History, 145, 219-302. 
Nonacs, P. 2000. Measuring and using skew in the study of social behavior and evolution. American Naturalist, 156, 577-589.

Nonacs, P. 2003. Measuring the reliability of skew indices: is there one best index? Animal Behaviour, 65, 615-627.

O'Keefe, K. J. \& Schwarz, M. P. 1990. Pheromones are implicated in reproductive differentiation in a primitively social bee. Naturwissenschaften, 77, 83-86.

Paxton, R. J., Ayasse, M., Field, J. \& Soro, A. 2002. Complex sociogenetic organization and reproductive skew in a primitively eusocial sweat bee, Lasioglossum malachurum, as revealed by microsatellites. Molecular Ecology, 11, 2405-2416.

Queller, D. C. \& Goodnight, K. F. 1989. Estimating relatedness using genetic markers. Evolution, 43, 258-275.

Ragsdale, J. E. 1999. Reproductive skew theory extended: the effect of resource inheritance on social organization. Evolutionary Ecology Research, 1, 859-874.

Reeve, H. K. 1998. Game theory, reproductive skew, and nepotism. In: Game Theory and Animal Behaviour (Ed. by L. A. Dugatkin \& H. K. Reeve), pp. 118-145. Oxford: Oxford University Press.

Reeve, H. K. 2000. A transactional theory of within-group conflict. American Naturalist, 155, 365-382.

Reeve, H. K. \& Emlen, S. T. 2000. Reproductive skew and group size: an N-person staying incentive model. Behavioral Ecology, 11, 640-647.

Reeve, H. K. \& Jeanne, R. L. 2003. From individual control to majority rule: extending transactional models of reproductive skew in animal societies. Proceedings of the Royal Society of London, Series B, 270, 1041-1045.

Reeve, H. K. \& Keller, L. 1995. Partitioning of reproduction in mother-daughter versus sibling associations: a test of optimal skew theory. American Naturalist, 145, 119-132.

Reeve, H. K. \& Keller, L. 2001. Tests of reproductive-skew models in social insects. Annual Review of Entomology, 46, 347-385.

Reeve, H. K. \& Nonacs, P. 1992. Social contracts in wasp societies. Nature, 359, 823-825.

Reeve, H. K. \& Ratnieks, F. L. W. 1993. Queen-queen conflicts in polygynous societies: mutual tolerance and reproductive skew. In: Queen Number and Sociality in Insects (Ed. by L. Keller), pp. 45-85. Oxford: Oxford University Press.

Reeve, H. K., Emlen, S. T. \& Keller, L. 1998. Reproductive sharing in animal societies: reproductive incentives or incomplete control by dominant breeders? Behavioral Ecology, 9, 267-278.

Reeve, H. K., Starks, P. T., Peters, J. M. \& Nonacs, P. 2000. Genetic support for the evolutionary theory of reproductive transactions in social wasps. Proceedings of the Royal Society of London, Series B, $267,75-79$.
Rettenmeyer, C. W. \& Watkins, J. F. 1978. Polygyny and monogyny in army ants (Hymenoptera: Formicidae). Journal of the Kansas Entomological Society, 51, 581-591.

Schwarz, M. P. 1986. Persistent multi-female nests in an Australian allodapine bee, Exoneura bicolor (Hymenoptera, Anthophoridae). Insectes Sociaux, 33, 258-277.

Schwarz, M. P. 1987. Intra-colony relatedness and sociality in the allodapine bee Exoneura bicolor. Behavioral Ecology and Sociobiology, 21, 387-392.

Schwarz, M. P. 1988. Local resource enhancement and sex-ratios in a primitively social bee. Nature, 331, 346-348.

Schwarz, M. P. 1994. Female-biased sex-ratios in a facultatively social bee and their implications for social evolution. Evolution, 48, 1684-1697.

Schwarz, M. P. \& Blows, M. W. 1991. Kin association during cofounding in the bee Exoneura bicolor: active discrimination, philopatry and familiar landmarks. Psyche, 98, 241-250.

Schwarz, M. P. \& O'Keefe, K. J. 1991a. Cooperative nesting and ovarian development in females of the predominantly social bee Exoneura bicolor Smith (Hymenoptera: Anthophoridae) after forced solitary eclosion. Journal of the Australian Entomological Society, 30, 251-255.

Schwarz, M. P. \& O'Keefe, K. J. 1991 b. Order of eclosion and reproductive differentiation in a social allodapine bee. Ethology Ecology and Evolution, 3, 233-245.

Schwarz, M. P. \& Woods, R. E. 1994. Order of adult eclosion is a major determinant of reproductive dominance in the allodapine bee Exoneura bicolor. Animal Behaviour, 47, 373-378.

Schwarz, M. P., Bull, N. J. \& Hogendoorn, K. 1998. Evolution of sociality in the allodapine bees: a review of sex allocation, ecology and evolution. Insectes Sociaux, 45, 349-368.

Seppa, P., Queller, D. C. \& Strassmann, J. E. 2002. Reproduction in foundress associations of the social wasp, Polistes carolina: conventions, competition, and skew. Behavioral Ecology, 13, 531-542.

Sherman, P. W., Lacey, E. A., Reeve, H. K. \& Keller, L. 1995. The eusociality continuum. Behavioral Ecology, 6, 102-108.

Sumner, S., Casiraghi, M., Foster, W. \& Field, J. 2002. High reproductive skew in tropical hover wasps. Proceedings of the Royal Society of London, Series B, 269, 179-186.

Tibbetts, E. A. \& Reeve, H. K. 2000. Aggression and resource sharing among foundresses in the social wasp Polistes dominulus: testing transactional theories of conflict. Behavioral Ecology and Sociobiology, 48, 344-352.

Vehrencamp, S. L. 1983. A model for the evolution of despotic versus egalitarian societies. Animal Behaviour, 31, 667-682. 